\title{
Jörg Riecke, Geschichte der deutschen Sprache. Eine Einführung
}

Héloïse Elisabeth Ducatteau

\section{OpenEdition}

\section{Journals}

Édition électronique

URL : https://journals.openedition.org/ifha/11404

DOI : 10.4000/ifha. 11404

ISSN : 2198-8943

\section{Éditeur}

IFRA - Institut franco-allemand (sciences historiques et sociales)

\section{Référence électronique}

Héloïse Elisabeth Ducatteau, « Jörg Riecke, Geschichte der deutschen Sprache. Eine Einführung », Revue de l'IFHA [En ligne], Date de recension, mis en ligne le 14 juin 2021, consulté le 16 juin 2021. URL : http://journals.openedition.org/ifha/11404 ; DOl : https://doi.org/10.4000/ifha.11404

Ce document a été généré automatiquement le 16 juin 2021.

(CIFHA 


\title{
Jörg Riecke, Geschichte der deutschen Sprache. Eine Einführung
}

\author{
Héloïse Elisabeth Ducatteau
}

Jörg Riecke, professeur de linguistique allemande à l'Université d'Heidelberg, nous a quitté.e.s en 2019 avant même ses 60 ans. Une monographie postérieure à la présente et dédiée à la toponymie a fait l'objet d'une recension en français par Thomas Niklas, enseignant-chercheur de l'Université de Reims ChampagneArdenne, dans la Revue d'Alsace.

L'ouvrage présent a une visée andragogique. Il est destiné à des germanistes non spécialistes d'histoire de la langue, à des étudiant.e.s des premiers semestres, à de simples curieux.ses. L'auteur est parti du constat que tous les ouvrages traitant du sujet n'étaient pas accessibles sans connaissances préalables. Il ne précise pas qu'il peut être

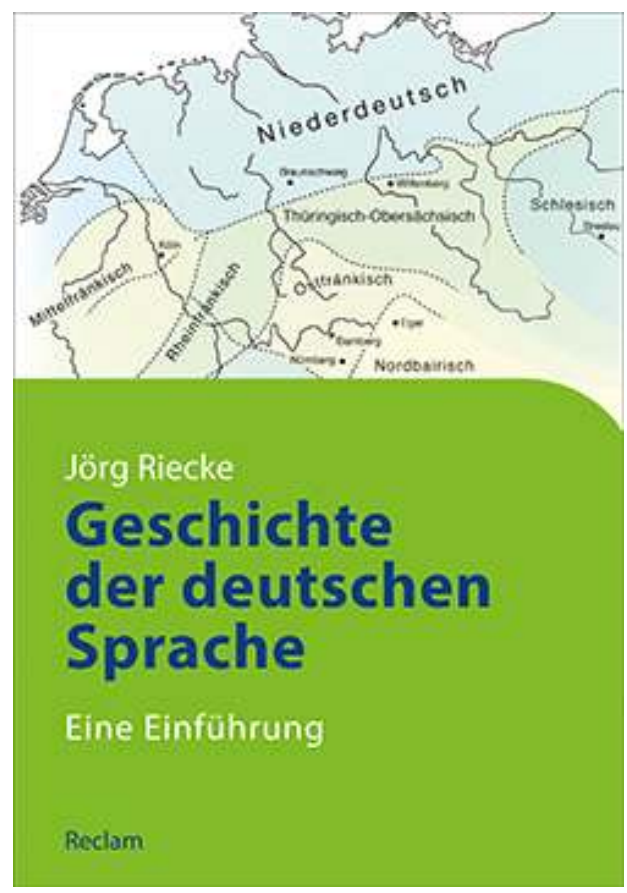
particulièrement adéquat pour des germanisant.e.s internationaux.les. En effet, l'histoire de la langue allemande occupe souvent une place mineure dans les études de germanistique en dehors des DACH-Länder.

Atout du livre : il dresse à la fois l'histoire externe et interne de la langue. Les débats linguistiques, les mesures institutionnelles viennent expliquer les mutations consonantiques, orthographiques... La division des chapitres de l'ouvrage correspond à chaque grand stade de l'idiome. Ce découpage est expliqué p.39. Le premier chapitre brosse l'arc temporel entre 750 et 1050, celui de l'ancien-haut-allemand, aussi nommé 
vieux-haut-allemand et vieil-haut-allemand. L'auteur explique bien sa délimitation avec le saxe, langue qui s'amenuisera jusqu'à être tenue pour dialecte sous le nom de Niederdeutsch et de Plattdütsch. L'influence du latin est mise en exergue à travers l'explicitation du fonctionnement des glosses pratiquées dans les monastères.

Le deuxième chapitre est logiquement dédié au moyen-haut-allemand (1050-1350) déjà introduit à la fin de la partie précédente lorsque la version en vieil-haut-allemand puis celle en moyen-haut-allemand de la Règle des Bénédictins sont exposées p.41. L'apport de l'adstrat du français est illustré à travers le poème satirique de Tannhäuser et la littérature chevaleresque dont Parzival est l'un des archétypes. De vulgari eloquentia, livre métalinguistique de Dante Alighieri, est utilement mobilisé pour sa différenciation entre langue haute et dialectes : une langue suprarégionale est encore un idéal à l'époque. Les variétés de l'allemand, du moyen-francique au francique rhénan en passant par le bavarois, s'étendaient au-delà de l'aire germanophone actuelle. Des ponts sont aussi établis avec de la littérature contemporaine quand il est par exemple question du vocable de Eigenschaft pour lequel l'empreinte de Maitre Eckhart et de Robert Musil six siècles plus tard est indéniable.

La troisième partie est focalisée sur le haut-allemand moderne (Jack Feuillet, Grammaire historique de l'allemand, 2012), aussi appelé nouveau-haut-allemand et nouvel-hautallemand (Nadia Mesli, Les locutions verbales dans les écrits de M. Luther, 1989), pratiqué entre 350 et 1650 . Une place importante y est accordée à la langue des chancelleries et à l'impact de Luther. Le rôle de l'imprimerie et des premières grammaires est aussi souligné notamment pour l'établissement des variétés. Des commentaires glottohistoriographiques gratifient Agathe Lasch, première femme professeure de germanistique en Allemagne, pour ses recherches pionnières sur la langue du XVI ${ }^{\mathrm{e}}$ siècle, assassinée en 1942 à Riga avant même son arrivée dans le ghetto.

La quatrième partie traite du nouvel-haut-allemand précoce (1650-1800). Face au gallotropisme trop prépondérant au goût de certain.e.s se dressent des puristes tels Moscherosch, Schorer, Grimmelshausen qui s'assemblent en comités comme la Teutschgesinnte Genossenschaft ou la Aurichtige Tannengesellschaft. C'est à partir du siècle des Lumières que l'allemand devient langue d'instruction dans les universités au détriment du latin.

La cinquième partie est centrée sur le nouvel-haut-allemand tardif (1800-1950). La littérature romantique revitalise des termes du vieux-haut-allemand tombés en désuétude comme Minne ou Märe. L'auteur révèle combien le terme même d'« allemand » était élargi à toutes les langues germaniques par les nationalistes.

Des cartes géographiques glissées entre l'indice des abréviations et la bibliographie renseignent sur les lieux-clé des trois premières strates linguistiques et non pour le haut-allemand moderne. Si la bibliographie enrichit de références supplémentaires la littérature secondaire déjà citée dans le texte courant, une différence de police ou des astérisques aurait permis de différencier les deux. La littérature primaire est totalement absente de la bibliographie. Cette dernière est suivie d'un répertoire de concepts qui contient le gothique mais pas le saxe, beaucoup plus proche linguistiquement et culturellement pourtant. Suit un index de personnes nettement plus exhaustif. 
INDEX

Thèmes : Histoire de la culture

Index chronologique : Ouvrages transpériodiques

\section{AUTEUR}

HÉLOÏSE ELISABETH DUCATTEAU

Université Savoie Mont Blanc 